\title{
Variability in Regional Ecological Vulnerability: A Case Study of Sichuan Province, China
}

\author{
Yimeng Liu ${ }^{1,2,3} \cdot$ Saini Yang ${ }^{1,2,3} \cdot$ Chuanliang $\mathrm{Han}^{4} \cdot$ Wei Ni ${ }^{1,2,3} \cdot$ Yuyao Zhu ${ }^{1,2,3}$
}

Published online: 3 September 2020

(C) The Author(s) 2020

\begin{abstract}
Rapid urbanization and natural hazards are posing threats to local ecological processes and ecosystem services worldwide. Using land use, socioeconomic, and natural hazards data, we conducted an assessment of the ecological vulnerability of prefectures in Sichuan Province for the years 2005,2010 , and 2015 to capture variations in its capacity to modulate in response to disturbances and to explore potential factors driving these variations. We selected five landscape metrics and two topological indicators for the proposed ecological vulnerability index (EVI), and constructed the EVI using a principal component analysis-based entropy method. A series of correlation analyses were subsequently performed to identify the factors driving variations in ecological vulnerability. The results show that: (1) for each of the study years, prefectures with high ecological vulnerability were located mainly in southern and eastern Sichuan, whereas prefectures in central and western Sichuan were of relatively low ecological vulnerability; (2) Sichuan's ecological
\end{abstract}

Saini Yang

yangsaini@bnu.edu.cn

1 Key Laboratory of Environmental Change and Natural Disaster, Ministry of Education, Beijing Normal University, Beijing 100875, China

2 State Key Laboratory of Earth Surface Processes and Resource Ecology, Beijing Normal University, Beijing 100875, China

3 Academy of Disaster Reduction and Emergency Management, Ministry of Emergency Management and Ministry of Education, Faculty of Geographical Science, Beijing Normal University, Beijing 100875, China

4 State Key Laboratory of Cognitive Neuroscience and Learning and IDG/McGovern Institute for Brain Research, Beijing Normal University, Beijing 100875, China vulnerability increased significantly $(p=0.011)$ during 2005-2010; (3) anthropogenic activities were the main factors driving variations in ecological vulnerability. These findings provide a scientific basis for implementing ecological protection and restoration in Sichuan as well as guidelines for achieving integrated disaster risk reduction.

Keywords Anthropogenic activities - Ecological vulnerability $\cdot$ Natural hazards · PCA-based entropy method · Rank correlation

\section{Introduction}

The concept of vulnerability has been applied widely in fields such as disaster studies (Yang et al. 2015; Li et al. 2016; Armaş et al. 2017), sustainable development (Turner et al. 2003), urban growth (Hong et al. 2016), and climate science (Cinner et al. 2013). Ecological vulnerability is generally conceptualized as the potential of an ecosystem to modulate its response to external interference and stressors at a specific spatial scale (Williams and Kapustka 2000; Qiu et al. 2015; Beroya-Eitner 2016). Research into ecological vulnerability has become an important aspect of study on sustainable development (Lin and Ho 2003). Spatial assessments of ecological vulnerability importantly enable the identification of areas that are vulnerable to disturbance, providing a basis for the formulation of measures aimed at controlling the degradation of ecological environments and promoting regional eco-environmental development (Ying et al. 2007; Qiao et al. 2013; Hou et al. 2015; Hong et al. 2016).

Ecological vulnerability assessment can be conducted at different hierarchical scales (De Lange et al. 2010), including population level (De Lange et al. 2009), 
community/habitat level (Ocaña et al. 2019), ecosystem level (Ippolito et al. 2010), and landscape level (Ding et al. 2018). The landscape level is considered a suitable scale for regional ecological vulnerability study (Qiu et al. 2007; Jiang et al. 2008), therefore we adopted the landscape-level ecological vulnerability assessment in this study to reveal regional ecological vulnerability distribution. A comprehensive indicator framework has been widely applied to evaluate ecological vulnerability at landscape level (Song et al. 2010; Zhang et al. 2014; Kumar et al. 2015), which is composed by two major parts.

The first part is establishing an ecological vulnerability indicator (EVI) system to reflect regional ecosystem vulnerability. An EVI system often entails the landscape metrics, which quantitatively describe the spatial characteristics of landscape pattern (Mörtberg et al. 2007; Qiao 2007). Qiu et al. (2007) incorporated landscape metrics of landscape isolation, fractal dimension, and fragmentation in the EVI system, to reflect the vulnerability of the ecoenvironment; Ortega et al. (2012) used metrics related to landscape composition and configuration to assess the landscape vulnerability to wildfire in Spain; Zang et al. (2017) applied landscape metrics of the number of patches, patch density, mean patch size, and class area to identify the impact of landscape pattern changes on regional ecological vulnerability. However, a shortcoming of landscape metrics is that they primarily focus on the landscape structure, while omitting its functions (Zang et al. 2017). Graph-based topological indicators may be more effective in bridging the gap between ecological structures and their functions (Kupfer 2012), offering a more systems-oriented approach for quantifying landscape processes and functions. However, to date, topological indicators have rarely been incorporated into EVI systems (Kupfer 2012). In this work, we combine landscape pattern information and topological indicators in an EVI system.

The second part is to determine the weights of indicators. Common methods applied to determine indicator weights include analytic hierarchy process (Song et al. 2010; Sahoo et al. 2019), artificial neural network (Oppio and Corsi 2017), and principle component analysis (PCA) (Uddin et al. 2019). We used a PCA-based entropy method to acquire the relatively objective weights for the EVI system.

Sichuan Province, with abundant natural resources, is not only an important ecological barrier in the upper reaches of the Yangtze River, but also one of the hotspots of ecological conservation research in the world (Fang 2019). Sichuan Province is the most important industrial center in western China, and is currently undergoing a rapid urbanization. At the end of 2010, the urbanization rate of the province was $40.18 \%$, increasing to $47.69 \%$ in 2015 (National Bureau of Statistics of China 2016). The urbanization speed of Sichuan Province was higher than the national average during the period of the 12th five-year plan (Chen 2017). Meanwhile, Sichuan is a natural hazardprone region. On 12 May 2008, the Ms 8.0 Wenchuan Earthquake struck the region, leading to a loss of 35,679 ha of forestland that comprised $7.66 \%$ of the total forest area in the province (Guo 2012; Wang, Fu et al. 2012). Rapid urbanization and frequent natural hazards and disasters threaten the local ecological environment, and ecological conservation has become an essential task.

An assessment of ecological vulnerability advances understanding of the process of change of ecological systems facing various external disturbances. Our aim was to combine landscape metrics and topological indicators derived from graph theory to establish an EVI system and apply it to evaluate the regional ecological vulnerability of Sichuan Province of 3 years: 2005, 2010, and 2015. Importantly, we sought to analyze the factors driving spatiotemporal variations in ecological vulnerability to promote the protection and restoration of local ecologies.

\section{Study Area and Data}

We first introduce the study area of Sichuan Province, then describe the data involved in the present study.

\subsection{Study Area}

Sichuan Province, located at $97^{\circ} 21^{\prime} \mathrm{E}$ to $108^{\circ} 31^{\prime} \mathrm{E}$ and $26^{\circ} 03^{\prime} \mathrm{N}$ to $34^{\circ} 19^{\prime} \mathrm{N}$, is situated in the upper reaches of the Yangtze River in southwestern China. The province covers an area of over $485,000 \mathrm{~km}^{2}$, and comprises two geographically distinct areas (Fig. 1a). The western part of Sichuan evidences a rugged terrain and a complex geological structure comprising numerous mountain ranges. By contrast, the eastern part of the province is mostly located within the Sichuan Basin, of which the westernmost part is the Chengdu Plain, and the easternmost part features a terrain comprising folds and valleys. The dramatic differences in the terrains lead to highly variable climate (Fig. 1b) and an abundance of natural resources.

\subsection{Data}

We used various kinds of data to conduct the assessment of Sichuan's ecological vulnerability and to identify factors driving variations in ecological vulnerability. Table 1 provides details on the datasets. Socioeconomic data include the annual statistics of gross domestic product (GDP), the number of industrial enterprises above the designated size (IEADS), highway mileage, and the urbanization rate of each prefecture. Natural hazards data include frequency of geological hazards and the magnitude 

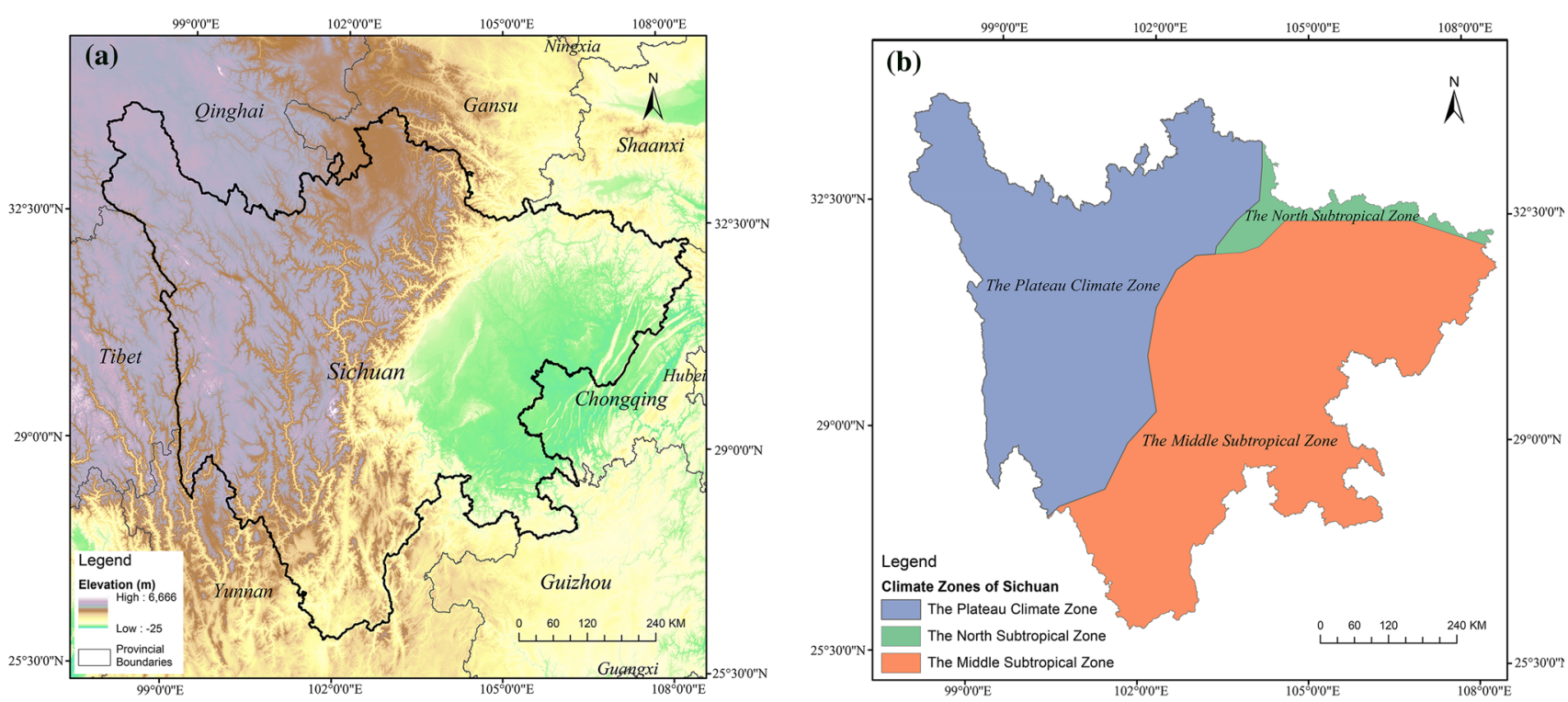

Fig. 1 The study area of Sichuan Province. a Elevation; b distribution of climate types in Sichuan Province. Source Adapted from the climate zone of China provided by the Data Center for Resources and Environmental Sciences, Chinese Academy of Sciences (RESDC) (http://www. resdc.cn)

Table 1 Information of dataset used in this study

\begin{tabular}{lll}
\hline Dataset & Source & Resolution \\
\hline $\begin{array}{l}\text { Land use/land cover } \\
\text { data }\end{array}$ & Geographical Information Monitoring Cloud Platform (http://www.dsac.cn/) & $30 \mathrm{~m}$ \\
NDVI & MODIS-based NDVI product & 16 -day, 250 m \\
NPP & MODIS-based NPP product & 8 -day, $1 \mathrm{~km}$ \\
Road network & National Geomatics Center of China (http://www.ngcc.cn/ngcc/) & $1: 400,000$ \\
Socioeconomic data & Sichuan Statistical Yearbook & Annual prefectural level statistical \\
& & data \\
Natural hazards data & China Earthquake Administration and Department of Natural Resources of & Annual prefectural level statistical \\
& Sichuan Province & data
\end{tabular}

NDVI normalized difference vegetation index; NPP net primary production

of earthquakes. All raster data were uniformly resampled to a resolution of $250 \mathrm{~m} \times 250 \mathrm{~m}$ for this study.

\section{Methodology}

We first identified ecological patches and then established an ecological network. We subsequently developed the EVI system, incorporating the attributes of landscape pattern and the topological attributes of ecological patches. Principal component analysis (PCA) and the entropy method were used to obtain the EVI.

\subsection{Identification of Ecological Patches}

An ecological patch is a relatively homogeneous area that differs from its surrounding areas (Pinto and Keitt 2009). By providing habitats and necessary resources for species, patches contribute significantly to the maintenance of biodiversity (Forman 1995). We applied the following three criteria (Kong et al. 2010; Yu et al. 2012; Lee et al. 2014) to identify ecological patches.

First, we defined ecological patches as comprising two land use/land cover types: (1) forestlands, including thick forests, open woodland, shrubbery, and immature plantations; and (2) grasslands with low, moderate, and high grass cover, respectively. Compared with other land cover types (for example, cropland and construction areas), 
forestland and grassland are subjected to lower degrees of anthropogenic disturbance, and provide multiple ecological services (Myers et al. 2000; Ellison et al. 2012).

Second, we set the minimum area of an ecological patch at $20 \mathrm{~km}^{2}$ based on the spatial scale of the study area and with reference to criteria adopted in previous studies (Kong et al. 2010; Yu et al. 2012; Lee et al. 2014).

Third, no two patches shared a common point or a common edge. We deemed patches within an ecological network should be spatially isolated from each other. It is assumed that if two patches shared common points or edges, they would be able to spontaneously exchange materials, energy, and information and could therefore be merged.

Applying the above criteria, we extracted ecological patches, calculated their landscape metrics, and established an ecological network for a topological analysis.

\subsection{Ecological Vulnerability Index System}

We selected representative indicators to construct the index system, which is the foundation of vulnerability analysis. The EVI system comprised five landscape metrics (total core area, landscape shape index, fragmentation of number, fragmentation of shape, and aggregation index) and two topological indicators (betweenness centrality and node vulnerability), respectively, depicting the landscape pattern and topological properties of patches.

\subsubsection{Landscape Metrics}

The five landscape metrics (Table 2) were calculated for each prefecture using the Fragstats 4 program (McGarigal et al. 2012). The positive indicators used in the calculation of the EVI were fragmentation of number, fragmentation of shape, and the landscape shape index, while the negative indicators were the total core area and aggregation index.

\subsubsection{Topological Indicators}

Topological indicators derived from graph theory can be used to measure the connectivity of patches. An ecological network can facilitate the topological analysis when it is analyzed as a graph, wherein the nodes and edges respectively represent ecological patches and corridors. The ecological network of Sichuan Province was established by two steps (Yu et al. 2012). The first step entailed the establishment of the cost surface, considering the following five factors: road density, construction areas, water bodies, vegetation coverage, and NPP. The second step entailed the establishment of potential corridors, indicating species' potential ability to disperse between patches. The least-cost path algorithm was applied to search for all potential dispersal corridors between each pair of patches. We subsequently applied Prim's algorithm to extract the minimum spanning tree representing the final ecological network.

We calculated two topological indicators based on the ecological network: betweenness centrality $(B C)$ and node vulnerability $(N V)$, and applied them in the EVI system. They are negative indicators for the calculation of EVI.

Betweenness centrality indicates the number of times that one node lies on the shortest paths of two other nodes. The node with the highest value of betweenness exerts the greatest control over the biological flow within the network (Estrada et al. 2009). Therefore, patches with higher $B C$ values are more resilient in the face of disturbances.

$\mathrm{BC}=\sum_{s \neq i \neq t} \frac{n_{s t}^{i}}{g_{s t}}$

where $g_{s t}$ denotes the number of the shortest paths between nodes $s$ and $t$ and $n_{s t}^{i}$ denotes the number of the shortest paths between nodes $s$ and $t$ passing through node $i$.

Node vulnerability indicates the loss of network efficiency after the removal of a single node from the network (Grubesic et al. 2008; Chen and Hero 2013; Hu et al. 2016). A higher $N V$ value of a node corresponds to a greater loss in efficiency with its removal.

$\mathrm{NV}=\frac{E-E_{i}}{E}$

$E=\frac{1}{N(N-1)} \sum_{i \neq j} \frac{1}{d_{i j}}$

where $E$ denotes the efficiency of the entire network, $E_{i}$ denotes the efficiency of the entire network after the removal of node $i$, and $d_{i j}$ is the cost distance between nodes $i$ and $j$.

\subsubsection{Principal Component Analysis}

We focused on the EVI at the prefectural level to capture regional differences in ecological vulnerability and, further, to identify their driving factors. Each indicator in the EVI system was calculated based on ecological patches and then assigned to the corresponding prefecture. For the calculation of landscape metrics, the ecological patches were first divided between the prefectures that they covered. Next, the ecological patches within each prefecture were separately entered into the FRAGSTATS software to obtain the landscape level metrics. For topological indicators, we first established the ecological network and subsequently calculated the two topological indicators for each patch. Last, we took the average value of the topological attributes for all of the patches within a prefecture as the topological attribute value for that prefecture. Inevitably, there were cases where one patch 
Table 2 Landscape metrics and their explanations

\begin{tabular}{|c|c|c|c|c|}
\hline Landscape metrics & Abbreviation & Equation & Description & References \\
\hline Total core area & TCA & $\mathrm{TCA}=\sum a_{i}$ & $a_{i}$ : core area of $i_{\mathrm{th}}$ patch in the landscape. & $\begin{array}{l}\text { Babí Almenar et al. } \\
\text { (2019) }\end{array}$ \\
\hline $\begin{array}{l}\text { Landscape shape } \\
\text { index }\end{array}$ & LSI & $\mathrm{LSI}=\frac{0.25 E}{\sqrt{A}}$ & $\begin{array}{l}E \text { : total length }(\mathrm{m}) \text { of edge in landscape } \\
A: \text { total landscape area. }\end{array}$ & $\begin{array}{l}\text { Lockhart and Koper } \\
\text { (2018) }\end{array}$ \\
\hline $\begin{array}{l}\text { Fragmentation of } \\
\text { number }\end{array}$ & FN & $\mathrm{FN}=\frac{\mathrm{NF}_{-1}}{\mathrm{MPS}}$ & $\begin{array}{l}\text { NF: the number of patches within a prefecture } \\
\text { MPS: mean patch size within a prefecture. }\end{array}$ & Qiu et al. (2007) \\
\hline $\begin{array}{l}\text { Fragmentation of } \\
\text { shape }\end{array}$ & FS & $\begin{array}{l}\mathrm{FS}=1-\frac{1}{\mathrm{MSI}} \\
\mathrm{MSI}=\frac{\mathrm{LSI}}{\mathrm{N}}\end{array}$ & $\begin{array}{l}\text { MSI: mean shape index of patch } \\
\text { LSI: landscape shape index } \\
N \text { : total number of patches within a landscape. }\end{array}$ & Jiang et al. (2013) \\
\hline Aggregation index & AI & $\mathrm{AI}=\frac{e_{i, i}}{{\max \_e_{i, i}}}$ & $\begin{array}{l}e_{i, i}: \text { the total edges shared by patch } i \text { itself } \\
{\max \_e_{i, i}: \text { the maximum aggregation level the landscape may }}_{\text {achieve. }}\end{array}$ & He et al. (2000) \\
\hline
\end{tabular}

simultaneously belonged to more than one prefecture. In such cases, the value of the topological indicator for this patch was applied in calculations for each prefecture to which it belonged.

Principal component analysis is an eigenvector-based method of reducing data dimensionality that was first proposed by Karl Pearson in 1901. It enables a multidimensional system to be simplified and condensed into a smaller set of orthogonal vectors known as principal components (Eq. 4).

$\left\{\begin{array}{l}Y_{1}=t_{11} X_{1}+t_{12} X_{2}+\cdots+t_{1 p} X_{p}=T_{1}^{\prime} X \\ Y_{2}=t_{21} X_{1}+t_{22} X_{2}+\cdots+t_{2 p} X_{p}=T_{2}^{\prime} X \\ \vdots \\ Y_{p}=t_{p 1} X_{1}+t_{p 2} X_{2}+\cdots+t_{p p} X_{p}=T_{p}^{\prime} X\end{array}\right.$

where $Y$ denotes the principal components, $T$ denotes the coefficient matrix, $X$ represents the raw data, and $p$ is the number of principal components. Each principal component explains a certain proportion of the total variance of the raw dataset, with components that demonstrate greater variance containing more information than those with less variance (Chen et al. 2013; Aksha et al. 2019). The number of retained principal components was determined according to the Kaiser criterion (eigenvalues > 1.00) (Yang et al. 2015).

\subsubsection{The Entropy Method}

Information entropy, proposed by Shannon in 1948, is a measure of the degree of disorder of a system. Building on this concept, the entropy method offers a relatively objective approach for determining weights. When there is a significant difference in the observed values for the same indicator, the corresponding entropy will be small, indicating that this indicator provides useful information.
Consequently, greater weight should be assigned to this kind of indicator; and the reverse situation also applies.

Usually, the potential correlation existing between indicators is not considered when applying the entropy method, which is a drawback of this method. To overcome this drawback, we established a model for evaluating vulnerability by combining PCA and the entropy method. In this model, the principal components obtained in the PCA are inputs for the entropy method. Equations 5 to 10 illustrate the calculation process of entropy method (Du et al. 2014; Zhang et al. 2014; Wang et al. 2018).

Assuming that there are $m$ principal components and $n$ prefectures forming an original matrix $Y_{i j(m \times n)}$, we first normalized the principal components using Eq. 5.

$Y_{i j}= \begin{cases}\left(Y_{i j}-\min \left\{Y_{i}\right\}\right) /\left(\max \left\{Y_{i}\right\}-\min \left\{Y_{i}\right\}\right), & \text { for positive indicators } \\ \left(\max \left\{Y_{i}\right\}-Y_{i j}\right) /\left(\max \left\{Y_{i}\right\}-\min \left\{Y_{i}\right\}\right), & \text { for negative indicators }\end{cases}$

The specific gravity value $Z_{i j}$ for each element $Y_{i j}$ is calculated using Eq. 6:

$Z_{i j}=\frac{Y_{i j}^{\prime}}{\sum_{i=1}^{m} Y_{i j}^{\prime}}$

Equation 7 is used to calculate the entropy of each principal component:

$e_{i}=-\frac{1}{\ln n} \sum_{j=1}^{n} Z_{i j} \times \ln Z_{i j}$

where $e_{i}$ denotes the entropy of the $i_{\text {th }}$ principal component.

The variation degree of each principal component, $d_{i}$, is measured using Eq. 8:

$d_{i}=1-e_{i}$

where $d$ denotes the variation degree of the $i_{\text {th }}$ principal component. 
Further, the weight of each principal component $w_{i}$ is calculated using the following formula:

$w_{i}=d_{i} / \sum_{i=1}^{m} d_{i}$

As a final step, we calculated the comprehensive index for assessing the ecological vulnerability of the $j_{\text {th }}$ prefecture as follows:

$\mathrm{EVI}_{j}=\sum_{i}^{m} w_{i} \times Y_{i j}$

where $\mathrm{EVI}_{j}$ is the EVI for the $j_{\text {th }}$ prefecture. Prefectures with higher EVI values demonstrated higher levels of ecological vulnerability and greater vulnerability in the face of external disturbances than those with lower EVI values.

\subsection{Correlation Analyses of Variations in Ecological Vulnerability and Disturbance Indicators}

We used the Spearman's rank correlation analysis to test the potential correlation between EVI changes and indicators of disturbance. The Spearman's rank correlation method hinges on the ranks of two groups of data and is not sensitive to outliers.

\subsubsection{Selection of Disturbance Indicators}

The prevailing consensus is that external disturbances caused by anthropogenic socioeconomic activities and natural hazards are likely to influence ecological vulnerability (Aswani and Lauer 2014; Xie et al. 2019). To further explore the key factors driving changes in ecological vulnerability, we selected four typical socioeconomic indicators and two natural hazard indicators.

\subsubsection{Socioeconomic Indicators}

1. The number of industrial enterprises above the designated size (IEADS): The IEADS is defined as stateowned and non-state-owned industrial companies with annual revenues above RMB 20 million yuan. In recent years, the industrial sector has played an important role in the rapid development of the Chinese economy, with IEADS emerging as the primary consumers of energy and the main providers of the municipal gross industrial product (Wang, Zeng et al. 2012).

2. Highway mileage (HM): Highway mileage reflects the developmental level of regional land transportation (Cao et al. 2016). These data include public motorable roads connecting prefectures, towns, and villages; the mileage of roads passing through urban streets, the lengths of highway bridges, the lengths of tunnels, and the widths of ferry crossings.

3. Gross domestic product (GDP): To ensure comparability of GDP data crossing years, we set 2005 as the benchmark year, and converted the data for 2010 and 2015 to the benchmark price in 2005 referring to the previous study of Lang et al. (2019).

4. Urbanization rate (UR): Urbanization rate is defined as the percentage of the population residing in urban areas. The increasing UR is likely to have impacts on ecological environments, resulting either in improved environmental efficiency or in barriers to the provision of ecosystem services (Ehrhardt-Martinez 1998).

Given that correlation analyses of EVI and socioeconomic variables are based on their relative changes, we calculated the percentage changes of EVI, and of each socioeconomic variable, for the periods 2005-2010 and 2010-2015.

\subsubsection{Natural Hazard Indicators}

1. Frequency of geological hazards (FGH): Geological hazards refer to rock fall, landslide, debris flow, unstable slopes, ground fissures, and ground subsidence in this study. The frequency of geological hazards of each prefecture was derived from the Sichuan Disaster Relief Yearbook (Disaster Relief Office of People's Government of Sichuan 2005), Sichuan Geological Environment Bulletin (Department of Land Resources of Sichuan 2010), and Sichuan Land and Resources Bulletin (Department of Natural Resources of Sichuan Province 2015).

2. Earthquake impact index (EII): This index was calculated for each prefecture for the periods 2005-2010 and 2010-2015 based on earthquake events with surface-wave magnitude (Ms) above 5.0. We referred to the report by the Technology Expert Group on Earthquake Relief, China National Commission for Disaster Reduction-The Ministry of Science and Technology (2008) to assign scores to earthquakes with various magnitude. Earthquakes above $M s 7.0$ usually affect a wide area. Prefectures located within severely-stricken, hard-stricken, and less-stricken areas were assigned a score of $0.6,0.3$, and 0.1 , respectively. Prefectures experienced earthquakes with magnitudes of $M s$ 5.0-5.9 and 6.0-6.9 were assigned a score of 0.1 and 0.3 , respectively. The scores of a prefecture for the periods 2005-2010, and 2010-2015 were summed to assess the impact of earthquakes during the corresponding period. 


\section{Results and Discussion}

In this section, we presented the spatial distribution (Sect. 4.1) and temporal variations (Sect. 4.2) of ecological vulnerability in Sichuan over the study years, and explored the possible factors that related to the ecological vulnerability variations (Sect. 4.3). Then the key findings were discussed.

\subsection{Spatial Distribution of Ecological Vulnerability}

Ecological patches showed similar patterns for all three study years. In terms of their spatial distribution, the patches were relatively concentrated in the northwestern part of the province, whereas they were scattered and sparse in the southern and eastern parts for each of these years (see Fig. 2a, illustrating the distribution of patches in 2010). Moreover, the total numbers and areas of the patches were similar for each of the 3 years. There were 228 patches in 2005 covering an area of $189,753 \mathrm{~km}^{2}, 248$ patches in 2010 covering an area of $184,299 \mathrm{~km}^{2}$, and 231 patches in 2015 with an area of $186,460 \mathrm{~km}^{2}$. In 2010 , the patches showed increasing fragmentation, with more patches covering a smaller area compared with their number and coverage in 2005 and 2015.

Figure $2 \mathrm{~b}$ shows the spatial distribution of EVI. The values of EVI are dimensionless, which have been normalized into 0 to 1 . Suining Prefecture was omitted because no patches were identified that fitted our criteria. Prefectures with high EVI values were mainly located in southern and eastern Sichuan, whereas prefectures with relatively low EVI values were mainly located in central and western Sichuan. For all 3 years, Guangyuan, Yibin, and Liangshan evidenced the highest degrees of ecological vulnerability. Patches in these prefectures were highly fragmented, relatively scattered, and small. By contrast, prefectures with widely distributed vegetation, such as Aba, Ganzi, and Ya'an, demonstrated relatively lower degrees of vulnerability.

\subsection{Temporal Variations of Ecological Vulnerability}

To understand differences in EVI values for the three study years, we performed the non-parametric Kruskal-Wallis one-way analysis of variance (Kruskal-Wallis one-way ANOVA) along with multiple comparison procedures (MCPs) using the MATLAB R2018b (student edition) software.

The result of Kruskal-Wallis one-way ANOVA revealed significant differences in EVI values for the 3 years $\left(\chi^{2}=9, p=0.011\right)$. The values obtained for the overall ecological vulnerability in 2010 and 2015 were significantly higher than the value for 2005 (Fig. 3).

The MCPs provided more detailed information about the differences between the medians of EVI of the 3 years. The EVI value in 2010 (median $=0.500$ ) was significantly higher than that in 2005 (median $=0.409$ ), since $p$ value $=0.0143<0.05=\alpha$. Thus, a significant increase in the EVI value corresponded to a significant increase in the degree of ecological degradation in Sichuan Province during this period. We also observed that the EVI variance in 2010 was greater than that in 2005, indicating that regional ecological vulnerability was more unevenly distributed and that intraregional differences in ecological vulnerability have amplified. During 2005-2010, the top three prefectures evidencing the highest EVI percentage changes were Deyang (58.1\%), Aba (57.7\%), and Panzhihua $(48.1 \%$ ) (Fig. 2a, underlined in blue; Table 3). Deyang and Aba are located in areas that were struck by the Wenchuan Earthquake (Fig. 2b). Considering previous studies (Guo 2012; Wang, Fu et al. 2012) have concluded that there was severe ecological damage after the Wenchuan Earthquake, we inferred that natural hazards may be a possible factor driving EVI change, and therefore involved natural hazards indicators in the correlation analysis.

The MCPs revealed that the difference between the EVI values in 2015 (median $=0.483$ ) and in 2010 was not significant, although there were local variations in EVI values. The difference between the EVI values in 2015 and 2005 was marginally significant $(p$ value $=0.051$ ). Thirteen out of 20 prefectures showed decreased EVI values between 2010 and 2015, and there was a small overall decrease comparing the median of 2015 with the median of 2010 (Fig. 3). However, the statistical results showed that the difference was insignificant. These findings imply that the ecological system has recovered to some extent, but it was still worse than the situation in 2005, indicating an urgent need for improved ecological conservation planning.

\subsection{Correlation Analysis Results}

We performed the Spearman's rank correlation analysis to test the potential correlation between EVI and indicators of disturbance. The results are shown in Fig. 4.

Compared with natural hazard indicators, changes in socioeconomic indicators were evidently more correlated to the EVI change (Fig. 4), indicating that human activities may be the main factors driving variations in ecological vulnerability. The result is coherent with a few previous studies (Li and Fan 2014; Liou et al. 2017), which concluded that anthropogenic activities indeed intensified the eco-environmental vulnerability. 
Fig. 2 Distribution of ecological patches and ecological vulnerability index (EVI) values in Sichuan Province. a The spatial distribution of ecological patches in 2010; $\mathbf{b}$ the distribution of EVI values in 2005, 2010, and 2015. The severely-stricken areas and the hard-stricken areas are short for severely-stricken areas of the Wenchuan Earthquake and hard-stricken areas of the Wenchuan Earthquake, which are provided by the Ministry of Civil Affairs of China

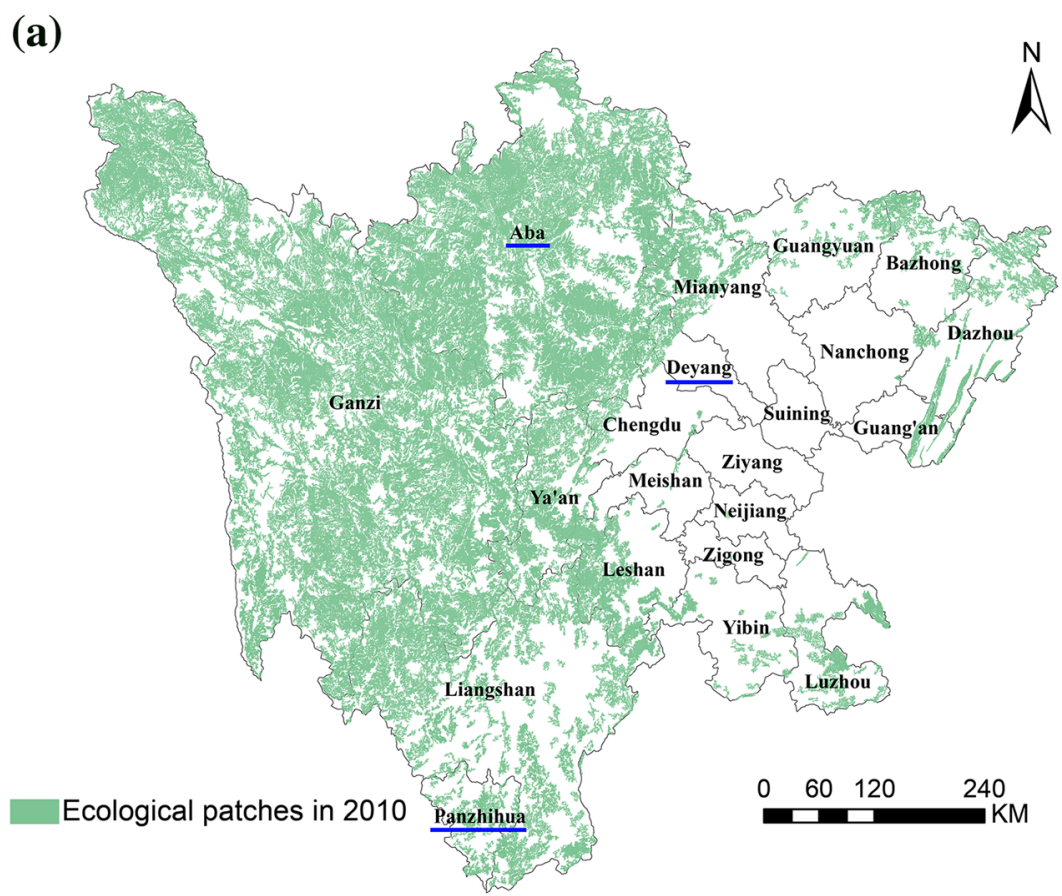

(b)

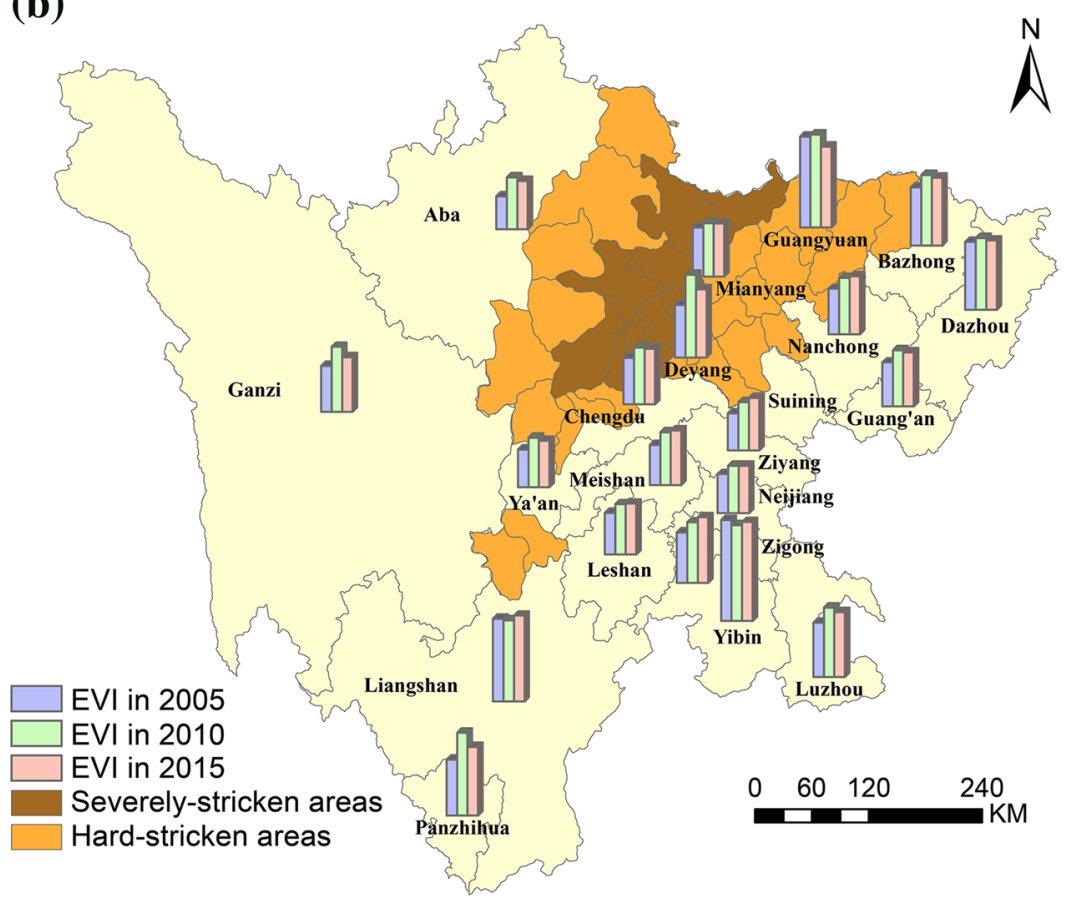

Of the four socioeconomic indicators, highway mileage and the number of IEADS, reflecting the intensity of human construction activities, are significantly correlated with the EVI (Fig. 4a, b). The rank correlation of the percentage change in the EVI and the percentage change in the number of IEADS was highly significant $(r=0.59$, $p<0.001$ ) (Fig. 4a). The likely reason is that productive activities within large-sized enterprises exert intensive and sustained impacts on the ecological environment in the long run. A significant positive rank correlation $(r=0.61$, $p<0.001)$ between the percentage change in the EVI and the percentage change in highway mileage was also observed (Fig. 4b). The construction of highways potentially results in continuous disruption of the original habitats and migration corridors of various species, thus shifting the landscape pattern and further reducing the efficiency of the exchange of materials and energy. A study of Hawbaker et al. (2006) showed a consistent result that 


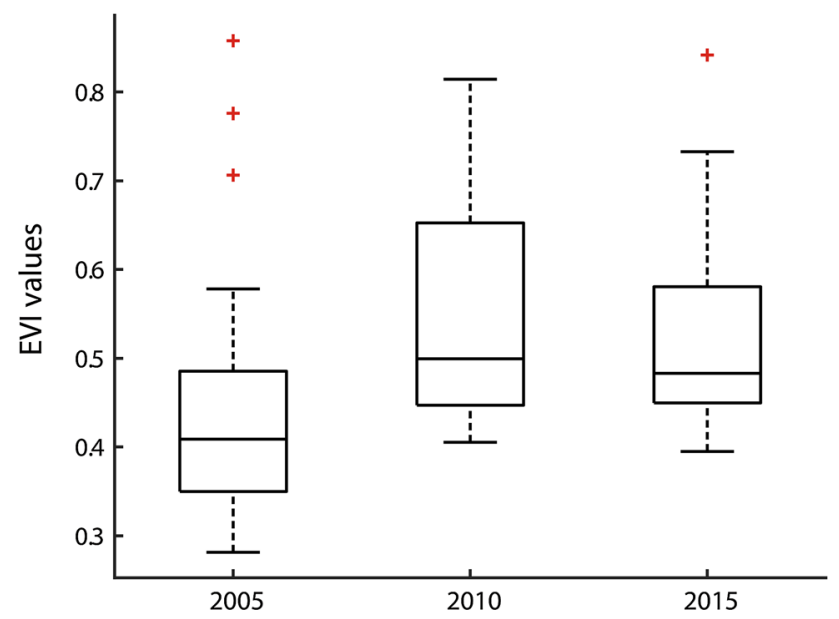

Fig. 3 Variations in ecological vulnerability index (EVI) values of Sichuan Province during the study years

roads remove habitat, alter adjacent areas, subdivide wildlife populations, as well as interrupt and redirect ecological flows. Li et al. (2010) also concluded that road construction influenced the local ecosystem by deteriorating landscape fragmentation. This finding calls for an indepth ecological impact assessment when planning construction projects.

Gross domestic product and urbanization rate, which provide more comprehensive macroscopic descriptions of socioeconomic development, did not show significant linear correlations with the EVI (Fig. 4c, d). This might be due to the fact that GDP and urbanization rate are related to multiple factors, so their relationships with EVI cannot be revealed by a linear correlation analysis.

None of the natural hazard indicators evidenced rank correlation with EVI (Fig. 4e, f), which suggests that ecosystems are resilient to natural disturbances on a long time scale. This result was echoed by Xiong et al. (2018): by 2015 , the average vegetation coverage in Wenchuan Earthquake stricken area had recovered to pre-earthquake level. Besides, we noticed that the influence of earthquakes on the EVI was even less significant than that of geological hazards. A possible explanation might be that earthquakes occurred less often than geological hazards, and the selfrepairing capacities of ecosystems enabled rapid recovery from disturbances of low frequency.

Although there was a catastrophic event,- - the Wenchuan Earthquake-during the period 2005-2010, a more significant factor contributing to increased EVI value might be the rapid increase in human construction activities. The construction activities contributed to a decline in the area of ecological patches and to severe fragmentation ( $\mathrm{Li}$ et al. 2018), thereby increasing ecological vulnerability. During the period 2010-2015, construction activities were reduced, and the overall ecological vulnerability decreased. In 2010-2015, although the majority of prefectural EVI values declined, EVI of Yibin, Lesha, and Ziyang Prefectures continued to increase. Simultaneously, highway mileage of these three cities increased by $43 \%, 35 \%$, and $25 \%$, respectively, ranking the first, second, and sixth among all cities in Sichuan. Since the change rate of highway mileage has a significant positive correlation with the EVI change rate, we infer that rapidly increasing highway mileage contributed to the continued increase of EVI in Yibin, Lesha, and Ziyang.

The result of EVI distribution provided a general description of ecological vulnerability situation in Sichuan Province. However, when it comes to assessing the vulnerability to a specific disturbance-for example, vulnerability to wildfire-the current EVI system may not be suitable. The EVI system needs to incorporate more eventspecific indicators-for example, the percentage of total landscape area covered by fine-grained forest-agriculture

Table 3 Ecological vulnerability index (EVI) values of each prefecture in Sichuan Province, 2005, 2010, and 2015

\begin{tabular}{|c|c|c|c|c|c|c|c|c|c|c|c|}
\hline \multirow[t]{2}{*}{ Prefecture } & \multicolumn{3}{|c|}{ EVI values } & \multicolumn{2}{|c|}{ Variations $(\%)$} & \multirow[t]{2}{*}{ Prefecture } & \multicolumn{3}{|c|}{ EVI values } & \multicolumn{2}{|c|}{ Variations $(\%)$} \\
\hline & 2005 & 2010 & 2015 & 2005-2010 & 2010-2015 & & 2005 & 2010 & 2015 & 2005-2010 & 2010-2015 \\
\hline Aba & 0.281 & 0.444 & 0.412 & 57.7 & -7.2 & Luzhou & 0.463 & 0.591 & 0.553 & 27.7 & -6.5 \\
\hline Bazhong & 0.496 & 0.601 & 0.577 & 21.1 & -4.0 & Meishan & 0.343 & 0.450 & 0.465 & 31.3 & 3.4 \\
\hline Chengdu & 0.398 & 0.485 & 0.475 & 22.0 & -2.2 & Mianyang & 0.420 & 0.454 & 0.451 & 8.1 & -0.5 \\
\hline Dazhou & 0.578 & 0.613 & 0.590 & 6.0 & -3.7 & Nanchong & 0.384 & 0.477 & 0.492 & 24.1 & 3.1 \\
\hline Deyang & 0.444 & 0.702 & 0.579 & 58.1 & -17.5 & Neijiang & 0.335 & 0.405 & 0.405 & 21.0 & -0.1 \\
\hline Ganzi & 0.391 & 0.555 & 0.465 & 41.9 & -16.1 & Panzhihua & 0.475 & 0.703 & 0.581 & 48.1 & -17.3 \\
\hline Guang'an & 0.374 & 0.478 & 0.460 & 27.8 & -3.8 & Ya'an & 0.321 & 0.421 & 0.395 & 31.1 & -6.3 \\
\hline Guangyuan & 0.776 & 0.794 & 0.690 & 2.3 & -13.1 & Yibin & 0.858 & 0.814 & 0.842 & -5.1 & 3.4 \\
\hline Leshan & 0.356 & 0.430 & 0.435 & 20.5 & 1.2 & Zigong & 0.428 & 0.514 & 0.557 & 20.0 & 8.5 \\
\hline Liangshan & 0.706 & 0.693 & 0.733 & -2.0 & 5.8 & Ziyang & 0.317 & 0.412 & 0.448 & 29.8 & 8.7 \\
\hline
\end{tabular}




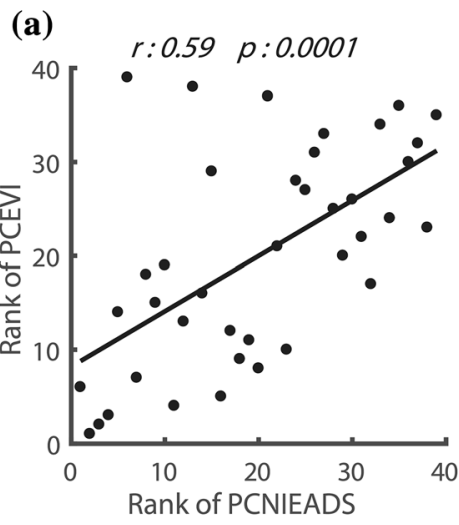

(b)

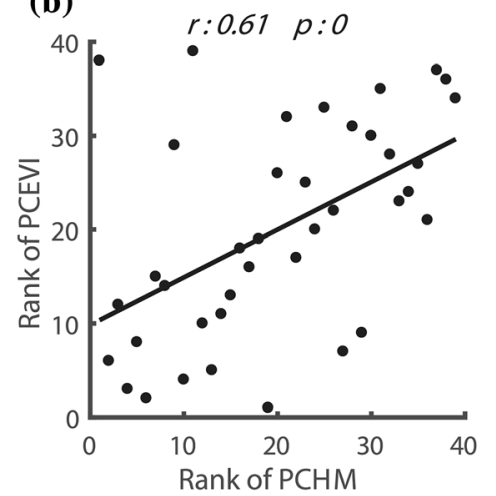

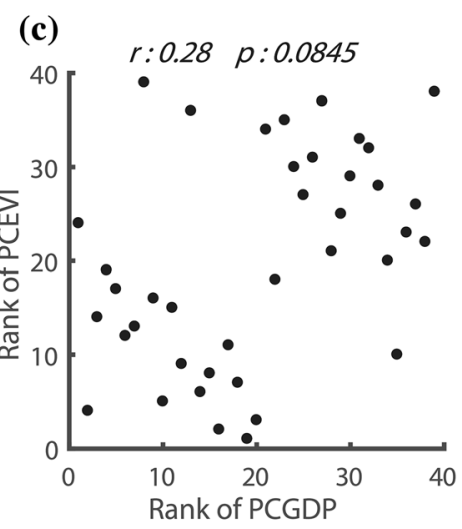

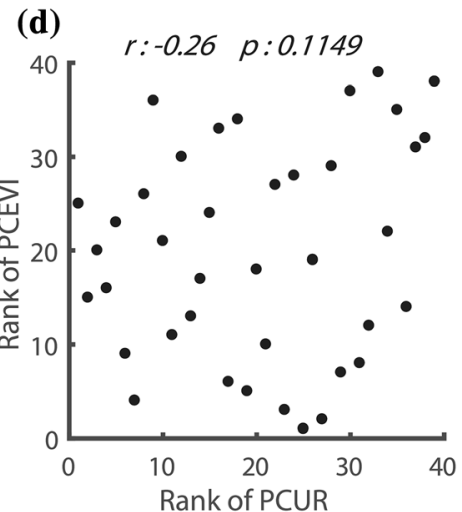

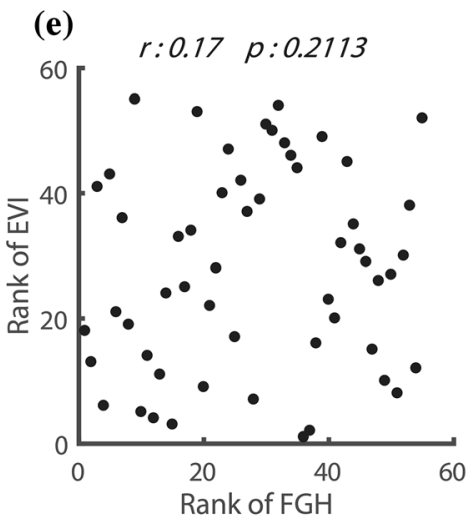

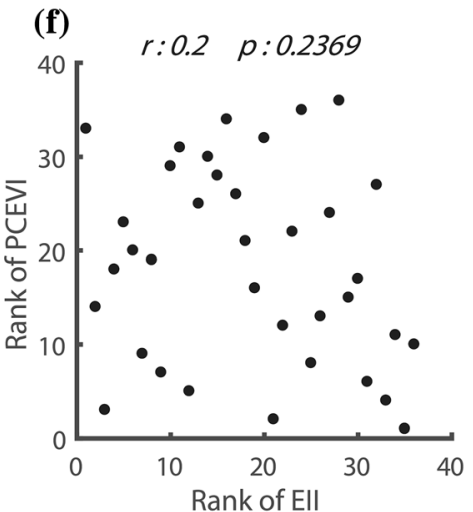

Fig. 4 Results of the Spearman's rank correlation test. PCEVI denotes the percentage change of the ecological vulnerability index; PCNIEADS denotes the percentage change of the number of industrial enterprises above the designated size; PCHM denotes the percentage change of highway mileage; PCGDP denotes the

mixtures and the total length of agricultural-forest edges per unit area (Ortega et al. 2012) to reflect the susceptibility of the ecological system to a specific disturbance. To further explore the potential relationship between EVI change and natural hazard factors, long-term studies on ecological vulnerability using higher resolution data on the intensity, frequency, and scope of various natural hazards are required. Additionally, this study did not involve much analysis between ecological vulnerability and land use/land cover changes or climate changes, which can become a crucial topic for future work.

\section{Conclusion}

In this study, we developed an integrated index system for assessing ecological vulnerability that combines landscape metrics with the topological attributes of ecological patches. The inclusion of topological attributes in a system for evaluating ecological vulnerability enables the quantification of both the landscape pattern and process, thereby contributing to a more holistic understanding of ecological vulnerability. A PCA-based entropy method was applied in percentage change of gross domestic product; PCUR denotes the percentage change of urbanization rate; FGH denotes the frequency of geological hazards; and EII denotes the earthquake impact index. $r$ correlation coefficient. $p$ significance of the correlation

the calculation of EVI to provide reasonable weight assignment and avoid correlations between indicators. We applied this index system in Sichuan Province to assess the ecological vulnerability of each prefecture for the years 2005, 2010, and 2015. The Spearman's rank correlation analysis was subsequently performed to determine the likely factors driving variations in ecological vulnerability. We conclude that:

1. Overall, the eastern and southern parts of Sichuan were more ecologically vulnerable than central and western Sichuan.

2. Ecological vulnerability in Sichuan significantly increased between 2005 and 2010 and stayed high during 2010 to 2015 , indicating an urgent need for improved ecological conservation planning.

3. Indicators related to intense human construction activities contributed more to variations in EVI than natural hazard indicators and macroscopic socioeconomic indicators. Among the socioeconomic indicators, the ones that concretely represent intense human activities (for example, highway mileage and the number of enterprises) were correlated more 
significantly with variations in ecological vulnerability than were macroscopic indicators (for example, urbanization rate and GDP). These findings indicate that in recent decades, intensive anthropogenic construction activities have been a key factor influencing the shift in landscape patterns and affecting ecological processes.

4. The proposed assessment framework provides a new method for ecological vulnerability analysis. The framework can be extended easily to multi-scale studies, and the indicator system can be adjusted to local contexts.

Acknowledgements This study is sponsored by the National Key Research Program of China (2016YFA0602403), the National Science Foundation (41621061), and the International Center for Collaborative Research on Disaster Risk Reduction (ICCR-DRR).

Open Access This article is licensed under a Creative Commons Attribution 4.0 International License, which permits use, sharing, adaptation, distribution and reproduction in any medium or format, as long as you give appropriate credit to the original author(s) and the source, provide a link to the Creative Commons licence, and indicate if changes were made. The images or other third party material in this article are included in the article's Creative Commons licence, unless indicated otherwise in a credit line to the material. If material is not included in the article's Creative Commons licence and your intended use is not permitted by statutory regulation or exceeds the permitted use, you will need to obtain permission directly from the copyright holder. To view a copy of this licence, visit http://creativecommons. org/licenses/by/4.0/.

\section{References}

Aksha, S.K., L. Juran, L.M. Resler, and Y. Zhang. 2019. An analysis of social vulnerability to natural hazards in Nepal using a modified social vulnerability index. International Journal of Disaster Risk Science 10(1): 103-116.

Armaş, I., D. Toma-Danila, R. Ionescu, and A. Gavriş. 2017. Vulnerability to earthquake hazard: Bucharest case study, Romania. International Journal of Disaster Risk Science 8(2): 182-195.

Aswani, S., and M. Lauer. 2014. Indigenous people's detection of rapid ecological change. Conservation Biology 28(3): 820-828.

Babí Almenar, J., A. Bolowich, T. Elliot, D. Geneletti, G. Sonnemann, and B. Rugani. 2019. Assessing habitat loss, fragmentation and ecological connectivity in Luxembourg to support spatial planning. Landscape and Urban Planning 189: 335-351.

Beroya-Eitner, M.A. 2016. Ecological vulnerability indicators. Ecological Indicators 60: 329-334.

Cao, M.T., D. Xu, F. Xie, E. Liu, and S. Liu. 2016. The influence factors analysis of households' poverty vulnerability in southwest ethnic areas of China based on the hierarchical linear model: A case study of Liangshan Yi Autonomous Prefecture. Applied Geography 66: 144-152.

Chen, L.M. 2017. Research on the coupling development between population and land urbanization in Sichuan Province. Journal of Chengdu Normal University 33(9): 58-63 (in Chinese).
Chen, P.Y., and A. Hero. 2013. Node removal vulnerability of the largest component of a network. In 2013 IEEE Global Conference on Signal and Information Processing, 587-590.

Chen, W.F., S.L. Cutter, C.T. Emrich, and P.J. Shi. 2013. Measuring social vulnerability to natural hazards in the Yangtze River Delta region, China. International Journal of Disaster Risk Science 4(4): 169-181.

Cinner, J.E., C. Huchery, E.S. Darling, A.T. Humphries, N.A.J. Graham, C.C. Hicks, N. Marshall, and T.R. McClanahan. 2013. Evaluating social and ecological vulnerability of coral reef fisheries to climate change. PLOS ONE 8(9): Article e74321.

De Lange, H.J., J. Lahr, J.J.C. Van Der Pol, Y. Wessels, and J.H. Faber. 2009. Ecological vulnerability in wildlife: An expert judgment and multicriteria analysis tool using ecological traits to assess relative impact of pollutants. Environmental Toxicology and Chemistry 28(10): 2233-2240.

De Lange, H.J., S. Sala, M. Vighi, and J.H. Faber. 2010. Ecological vulnerability in risk assessment-A review and perspectives. Science of the Total Environment 408(18): 3871-3879.

Department of Land Resources of Sichuan. 2010. Sichuan geological environment bulletin. Chengdu, China: Department of Land Resources of Sichuan.

Department of Natural Resources of Sichuan Province. 2015. Sichuan land and resources bulletin. Chengdu, China: Department of Natural Resources of Sichuan Province.

Ding, Q., X. Shi, D.F. Zhuang, and Y. Wang. 2018. Temporal and spatial distributions of ecological vulnerability under the influence of natural and anthropogenic factors in an eco-province under construction in China. Sustainability 10(9): Article 3087.

Disaster Relief Office of People's Government of Sichuan. 2005. Sichuan disaster relief yearbook. Chengdu, China: Disaster Relief Office of People's Government of Sichuan.

Du, Y.P., Y. Zhang, X.G. Zhao, and X.H. Wang. 2014. Risk evaluation of bogie system based on extension theory and entropy weight method. Computational Intelligence and Neuroscience 2014: Article 195752.

Ehrhardt-Martinez, K. 1998. Social determinants of deforestation in developing countries: A cross-national study. Social Forces 77(2): 567-586.

Ellison, D., M.N. Futter, and K. Bishop. 2012. On the forest coverwater yield debate: From demand- to supply-side thinking. Global Change Biology 18(3): 806-820.

Estrada, E., D.J. Higham, and N. Hatano. 2009. Communicability betweenness in complex networks. Physica A: Statistical Mechanics and its Applications 388(5): 764-774.

Fang, Y. 2019. The current situation of land use in Sichuan forestry nature reserves. Journal of Sichuan Forestry Science and Technology 40(2): 80-83 (in Chinese).

Forman, R.T.T. 1995. Some general principles of landscape and regional ecology. Landscape Ecology 10(3): 133-142.

Grubesic, T.H., T.C. Matisziw, A.T. Murray, and D. Snediker. 2008. Comparative approaches for assessing network vulnerability. International Regional Science Review 31(1): 88-112.

Guo, Y. 2012. Urban resilience in post-disaster reconstruction: Towards a resilient development in Sichuan, China. International Journal of Disaster Risk Science 3(1): 45-55.

Hawbaker, T.J., V.C. Radeloff, M.K. Clayton, R.B. Hammer, and C.E. Gonzalez-Abraham. 2006. Road development, housing growth, and landscape fragmentation in northern Wisconsin: 1937-1999. Ecological Applications 16(3): 1222-1237.

He, H.S., B.E. DeZonia, and D.J. Mladenoff. 2000. An aggregation index (AI) to quantify spatial patterns of landscapes. Landscape Ecology 15(7): 591-601.

Hong, W.Y., R.R. Jiang, C.Y. Yang, F.F. Zhang, M. Su, and Q. Liao. 2016. Establishing an ecological vulnerability assessment indicator system for spatial recognition and management of 
ecologically vulnerable areas in highly urbanized regions: A case study of Shenzhen, China. Ecological Indicators 69: 540-547.

Hou, K., X.X. Li, and J. Zhang. 2015. GIS analysis of changes in ecological vulnerability using a SPCA model in the Loess Plateau of Northern Shaanxi, China. International Journal of Environmental Research and Public Health 12(4): 4292-4305.

Hu, F.Y., C.H. Yeung, S.N. Yang, W.P. Wang, and A. Zeng. 2016. Recovery of infrastructure networks after localised attacks. Scientific Reports 6: Article 24522.

Ippolito, A., S. Sala, J.H. Faber, and M. Vighi. 2010. Ecological vulnerability analysis: A river basin case study. Science of the Total Environment 408(18): 3880-3890.

Jiang, M., W. Gao, X.W. Chen, X.F. Zhang, and W.X. Wei. 2008. Analysis of ecological vulnerability based on landscape pattern and ecological sensitivity: A case of Duerbete County. Proceedings of SPIE-The International Society for Optical Engineering 7083: Article 708315-11 (in Chinese).

Jiang, P.H., R.F. Zhao, H.L. Zhao, L.P. Lu, and Z.L. Xie. 2013. Relationships of wetland landscape fragmentation with climate change in middle reaches of Heihe River, China. Chinese Journal of Applied Ecology 24(6): 1661-1668 (in Chinese).

Kong, F.H., H.W. Yin, N. Nakagoshi, and Y.G. Zong. 2010. Urban green space network development for biodiversity conservation: Identification based on graph theory and gravity modeling. Landscape and Urban Planning 95(1-2): 16-27.

Kumar, R., G. Bala, N.H. Ravindranath, S. Upgupta, J. Sharma, and R.K. Chaturvedi. 2015. Assessment of inherent vulnerability of forests at landscape level: A case study from Western Ghats in India. Mitigation and Adaptation Strategies for Global Change 22(1): 29-44.

Kupfer, J.A. 2012. Landscape ecology and biogeography: Rethinking landscape metrics in a post-FRAGSTATS landscape. Progress in Physical Geography 36(3): 400-420.

Lang, C., M.T. Gao, G.C. Wu, and X.Y. Wu. 2019. The concentration of population and GDP in high earthquake risk regions in China: Temporal-spatial distributions and regional comparisons from 2000 to 2010. Pure and Applied Geophysics 176(10): $4161-4175$.

Lee, J.A., J. Chon, and C. Ahn. 2014. Planning landscape corridors in ecological infrastructure using least-cost path methods based on the value of ecosystem services. Sustainability 6(11): $7564-7585$.

Li, J.L., Y.C. Liu, R.L. Pu, Q.X. Yuan, X.L. Shi, Q.D. Guo, and X.Y. Song. 2018. Coastline and landscape changes in bay areas caused by human activities: A comparative analysis of Xiangshan Bay, China and Tampa Bay, USA. Journal of Geographical Sciences 28(8): 1127-1151.

Li, P.X., and J. Fan. 2014. Regional ecological vulnerability assessment of the Guangxi Xijiang River Economic Belt in southwest China with VSD model. Journal of Resources and Ecology 5(2): 163-170.

Li, T., F. Shilling, J. Thorne, F.M. Li, H. Schott, R. Boynton, and A.M. Berry. 2010. Fragmentation of China's landscape by roads and urban areas. Landscape Ecology 25(6): 839-853.

Li, X.L., L. Wang, and S. Liu. 2016. Geographical analysis of community resilience to seismic hazard in southwest China. International Journal of Disaster Risk Science 7(3): 257-276.

Lin, G.C.S., and S.P.S. Ho. 2003. China's land resources and land-use change: Insights from the 1996 land survey. Land Use Policy 20(2): 87-107.

Liou, Y., A.K. Nguyen, and M.H. Li. 2017. Assessing spatiotemporal eco-environmental vulnerability by Landsat data. Ecological Indicators 80: 52-65.

Lockhart, J., and N. Koper. 2018. Northern prairie songbirds are more strongly influenced by grassland configuration than grassland amount. Landscape Ecology 33(9): 1543-1558.
McGarigal, K., S.A. Cushman, M.C. Neel, and E. Ene. 2012. FRAGSTATS v4: Spatial pattern analysis program for categorical and continuous maps. Amherst, MA: University of Massachusetts. http://www.umass.edu/landeco/research/fragstats/ fragstats.html. Accessed 15 Dec 2018.

Myers, N., R.A. Mittermeier, C.G. Mittermeier, G.A.B. da Fonseca, and J. Kent. 2000. Biodiversity hotspots for conservation priorities. Nature 403(6772): 853-858.

Mörtberg, U.M., B. Balfors, and W.C. Knol. 2007. Landscape ecological assessment: A tool for integrating biodiversity issues in strategic environmental assessment and planning. Journal of Environmental Management 82(4): 457-470.

National Bureau of Statistics of China. 2016. China statistical yearbook 2016. Beijing, China: National Bureau of Statistics of China.

Ocaña, F.A., D. Pech, N. Simões, and I. Hernández-Ávila. 2019. Spatial assessment of the vulnerability of benthic communities to multiple stressors in the Yucatan Continental Shelf, Gulf of Mexico. Ocean \& Coastal Management 181: Article 104900.

Oppio, A., and S. Corsi. 2017. Territorial vulnerability and local conflicts perspectives for waste disposals siting. A case study in Lombardy region (Italy). Journal of Cleaner Production 141: $1528-1538$.

Ortega, M., S. Saura, S. González-Avila, V. Gómez-Sanz, and R. Elena-Rosselló. 2012. Landscape vulnerability to wildfires at the forest-agriculture interface: Half-century patterns in Spain assessed through the SISPARES monitoring framework. Agroforestry Systems 85(3): 331-349.

Pinto, N., and T.H. Keitt. 2009. Beyond the least-cost path: Evaluating corridor redundancy using a graph-theoretic approach. Landscape Ecology 24(2): 253-266.

Qiao, Q. 2007. Research on landscape pattern and ecological frangibility assessment of Chuan-Dian farming-pastoral zone. Beijing: Beijing Forestry University (in Chinese).

Qiao, Z., X. Yang, J. Liu, and X.L. Xu. 2013. Ecological vulnerability assessment integrating the spatial analysis technology with algorithms: A case of the wood-grass ecotone of northeast China. Abstract and Applied Analysis 2013: Article 207987.

Qiu, B.K., H.L. Li, M. Zhou, and L. Zhang. 2015. Vulnerability of ecosystem services provisioning to urbanization: A case of China. Ecological Indicators 57: 505-513.

Qiu, P.H., S.J. Xu, G.Z. Xie, B.N. Tang, H. Bi, and L.S. Yu. 2007. Analysis of the ecological vulnerability of the western Hainan Island based on its landscape pattern and ecosystem sensitivity. Acta Ecologica Sinica 27(4): 1257-1264.

Sahoo, S., A. Dhar, A. Debsarkar, and A. Kar. 2019. Future scenarios of environmental vulnerability mapping using grey analytic hierarchy process. Natural Resources Research 28(4): 1461-1483.

Song, G.B., Y. Chen, M.R. Tian, S.H. Lv, S.S. Zhang, and S.L. Liu. 2010. The ecological vulnerability evaluation in southwestern mountain region of China based on GIS and AHP method. Procedia Environmental Sciences 2: 465-475.

Technology Expert Group on Earthquake Relief, China National Commission for Disaster Reduction-The Ministry of Science and Technology. 2008. Comprehensive analysis and assessment of Wenchuan Earthquake. Beijing: Science Press.

Turner, B.L., R.E. Kasperson, P.A. Matson, J.J. McCarthy, R.W. Corell, L. Christensen, N. Eckley, J.X. Kasperson, et al. 2003. A framework for vulnerability analysis in sustainability science. Proceedings of the National Academy of Sciences 100(14): 8074-8079.

Uddin, M.N., A.K.M.S. Islam, S.K. Bala, G.M.T. Islam, S. Adhikary, D. Saha, S. Haque, M.G.R. Fahad, and R. Akter. 2019. Mapping of climate vulnerability of the coastal region of Bangladesh 
using principal component analysis. Applied Geography 102: 47-57.

Wang, Y.K., B. Fu, and P. Xu. 2012. Evaluation the impact of earthquake on ecosystem services. Procedia Environmental Sciences 13(1): 954-966.

Wang, Z.H., H.L. Zeng, Y.M. Wei, and Y.X. Zhang. 2012. Regional total factor energy efficiency: An empirical analysis of industrial sector in China. Applied Energy 97: 115-123.

Wang, Z.X., D.D. Li, and H.H. Zheng. 2018. The external performance appraisal of China energy regulation: An empirical study using a TOPSIS method based on entropy weight and Mahalanobis distance. International Journal of Environmental Research and Public Health 15(2): Article 236.

Williams, L.R.R., and L.A. Kapustka. 2000. Ecosystem vulnerability: A complex interface with technical components. Environmental Toxicology and Chemistry 19(4): 1055-1058.

Xie, Z.L., X.Z. Li, D.G. Jiang, S.W. Lin, B. Yang, and S.L. Chen. 2019. Threshold of island anthropogenic disturbance based on ecological vulnerability assessment-A case study of Zhujiajian Island. Ocean and Coastal Management 167: 127-136.

Xiong, J.N., C. Peng, C.K. Fan, M. Sun, Z.Q. Liu, and Y. Gong. 2018. Dynamic monitoring of vegetation fraction change in disaster area of Wenchuan Earthquake based on MODIS time-series data. Journal of Basic Science and Engineering 26(1): 60-69 (in Chinese).

Yang, S.N., S. He, J. Du, and X.H. Sun. 2015. Screening of social vulnerability to natural hazards in China. Natural Hazards 76(1): $1-18$.

Ying, X., G.M. Zeng, G.Q. Chen, L. Tang, K.L. Wang, and D.Y. Huang. 2007. Combining AHP with GIS in synthetic evaluation of eco-environment quality-A case study of Hunan Province, China. Ecological Modelling 209(2): 97-109.

Yu, D.Y., B. Xun, P.J. Shi, H.B. Shao, and Y.P. Liu. 2012. Ecological restoration planning based on connectivity in an urban area. Ecological Engineering 46: 24-33.

Zang, Z., X.Q. Zou, P. Zuo, Q.C. Song, C.L. Wang, and J.J. Wang. 2017. Impact of landscape patterns on ecological vulnerability and ecosystem service values: An empirical analysis of Yancheng Nature Reserve in China. Ecological Indicators 72(72): $142-152$

Zhang, X.Q., C.B. Wang, E.K. Li, and C.D. Xu. 2014. Assessment model of ecoenvironmental vulnerability based on improved entropy weight method. The Scientific World Journal 2014: Article 797814. 